\title{
Exploring the Access and Equity dimensions of Quality Education in the context of SDGs Lessons from DFID's Education Sector Support Programme in Nigeria
}

\author{
Ronke Ogunmakin* \\ Department of Educational Foundation, Faculty of Education, National Open University of Nigeria, Lagos, Nigeria \\ *Corresponding author: tanronng@yahoo.com
}

\begin{abstract}
This paper aims to explore the nexus between quality learning at the primary level of education, access and equity. A stratified sampling design was used. The survey covered primary schools in the six ESSPIN statesEnugu, Jigawa, Kaduna, Kano and Lagos. The sampling frame was compiled using the annual school census (ASC) with stratification by ESSPIN phases and whether or not the schools had participated in an earlier attempt to measure learning outcomes. Teachers were randomly sampled within selected schools in the survey. Teachers within each school were sampled from the population present in the school on the day of the survey visit and from those teaching grades 1-6 in the present term, using the school's teacher attendance register. Pupils were sampled from the pupil registers for grade 2 and 4 classes. The research confirmed that ESSPIN schools are performing better than the control schools on inclusiveness, spatial inclusion, and children's inclusiveness. There are evidences that the poorest children are benefiting disproportionately from ESSPIN, and that ESSPIN schools have smaller wealth disparities than non-ESSPIN ones. Disparities in pupil's learning outcomes in rural vis-à-vis urban schools were significant. Similarly, pupils from 'poorer' backgrounds performed starkly worse than others.
\end{abstract}

Keywords: quality, access, equity and learning

Cite This Article: Ronke Ogunmakin, "Exploring the Access and Equity dimensions of Quality Education in the context of SDGs Lessons from DFID's Education Sector Support Programme in Nigeria." American Journal of Educational Research, vol. 6, no. 4 (2018): 288-296. doi: 10.12691/education-6-4-1.

\section{Introduction}

Many Nigerian children remain out of school in spite of considerable government investments in access initiatives since the 1970s. Nigeria has the highest population of out of school children (OOSC) in the world, estimated at $18 \%$ of the world's 58 million. The estimated primary school aged population is 30 million, including 14.5 million girls (34\% of which are out of school) and 15.1 million boys (29\% of which are out of school ESSPIN [1] Most out of school children live in rural areas and come from poor households. Issues of gender, disability, child protection and increasingly conflict, throw up further barriers to the education of the poorest children. If Nigeria's education system is to work, it will need to orient itself to the circumstances of these excluded and marginalised children, overcoming the barriers they face to taking part in learning.

Since its inception in 2009, according to Hama [2] ESSPIN has offered a range of approaches to partners to boost the educational participation of the most excluded children. Different strategies have been piloted at different levels in the six ESSPIN-supported states, to test which approaches are most relevant to local and state level capacities and attitudes. At the start of ESSPIN there was concern that promoting inclusion and participation of the most excluded children (particularly girls, those with disabilities and ethnic minority children), might have a negative impact on quality. Therefore a flexible approach of offering different models and entry points for working on inclusion was used, with emphasis on maximum adaptability of approaches which have worked elsewhere.

\subsection{Why is UK Support Required?}

Learning outcomes in Nigeria are very low and access to basic education is limited:

- 10.5 million Children are out of a school in Nigeria - the highest number of any country in the world. Most of these children are in Northern Nigeria and the majority is girls.

- 23.1 million Children are in school but learning little. Pupils lack the foundation skills they require by the end of Grade 2 and so cannot cope with Years 3-4 curricula. Pupils reaching the required standard in Grade 2 English ranged from only $38 \%$ in Lagos to just 8\% in Kano.

- Teaching standards are extremely low. Out of 20,000 teachers in Kwara State, only 75 teachers had sufficient working knowledge to enable them to teach the Grade 4-6 curriculum for 9-11 year olds. Only 17 teachers in Lagos were capable and there were no teachers at all in Jigawa and Kano States. 
The extension of ESSPIN will allow DFID Nigeria to deliver commitments in its Operational Plan (2010-15). In the first year of the extension (2014-5), an additional 300,000 children will have benefitted from ESSPIN support, contributing to the achievement of the UK target that an additional 800,000 Nigerian children will be supported to enrol in school from 2010 to 2015.

\subsection{Theory of Change and Assessing the Evidence Base}

The problem that ESSPIN is helping to address is the very low level of learning outcomes in Nigeria's basic education system. This is caused by the poor quality of teaching, compounded by the constraints on access to basic education especially for the poor, for girls and for other disadvantaged groups. Girard [3]. ESSPIN's approach to addressing these challenges is to work strategically with all three levels of Government (Federal, State and Local) to adopt an integrated, multifaceted reform programme with improving school performance as the central focus. ESSPIN's School Improvement Programme (SIP) includes the following five pillars, with four cross cutting areas for capacity development.

The main assumption underpinning this integrated approach, according to Megill, [4] is that ESSPIN, by piloting an effective school improvement model with demonstrable results, will secure state government buy-in and convince States to utilise their own considerable resources to expand the positive impact of the model to all children.

\subsection{Sustainable Development Goals 2015-2030}

In detail, Lewin and Ricardo (13) revealed that world leaders are working to ensure that by 2030, all girls and boys complete free, equitable and quality primary and secondary education leading to relevant and effective learning outcomes; that all girls and boys have access to quality early childhood development, care and pre-primary education so that they are ready for primary education.

SDG 4 also seeks to ensure equal access for all women and men to affordable and quality technical, vocational and tertiary education, including university; Substantially increase the number of youth and adults who have relevant skills, including technical and vocational skills, for employment, decent jobs and entrepreneurship; Eliminate gender disparities in education and ensure equal access to all levels of education and vocational training for the vulnerable, including persons with disabilities, indigenous peoples and children in vulnerable situations.

Governments at various levels are not acquainted enough with the global urgency and exigency for meeting the SDG Goal 4; there does not appear to be any concerted focus on the part of governments to take the SDGs seriously. And Johnson, Hsieh and Onibon [5] observed that as at yet, the efforts made in that direction are so feeble they can only pass for lip service.

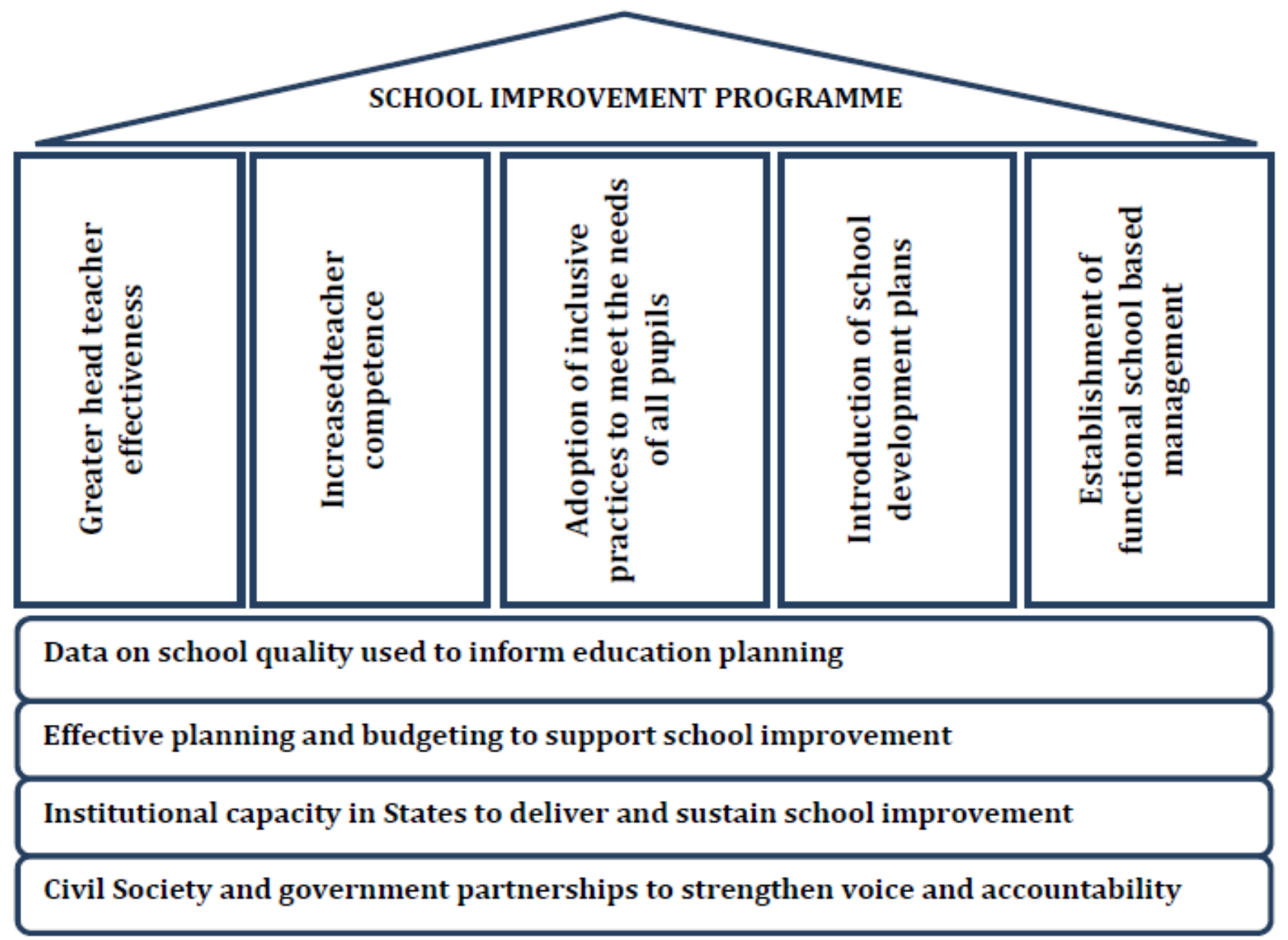

Figure 1. 
SDG Goal 4

- By 2030, ensure that all girls and boys complete free, equitable and quality primary and secondary education leading to relevant and effective learning outcomes

- By 2030 ensure that all girls and boys have access to quality early childhood development, care and pre-primary education so that they are ready for primary education

- By 2030 ensure equal access for all women and men to affordable quality technical, vocational and tertiary education, including university

- By 2030 , increase by $x \%$ the number of youth and adults who have relevant skills, including technical and vocational skills, for employment, decent jobs and entrepreneurship

- By 2030, eliminate gender disparities in education and ensure equal access to all levels of education and vocational training for the vulnerable, including persons with disabilities, indigenous peoples, and children in vulnerable situations

- By 2030 ensure that all youth and at least $\mathrm{x} \%$ of adults, both men and women, achieve literacy and numeracy

By 2030 ensure all learners acquire knowledge and skills needed to promote sustainable development, including among others through education for sustainable development and sustainable lifestyles, human rights, gender equality, promotion of a culture of peace and non-violence, global citizenship, and Obanya [6] observed that one major problem with Nigeria's ambitious UBE programme is that access was seen in its restrictive sense of enrolment figures. While there have been marginal increases in enrolment, issues concerning equity, quality and efficiency have not received adequate attention. The enrolment increases have not even tackled the problem of Exclusion, as a large proportion of school-age children are still enrolled.

According to Lewin and Sabate [7] Initial access has little meaning unless it results in:

1. Secure enrolment and regular attendance;

2. Progression through grades at appropriate ages;

3. Meaningful learning which has utility;

4. Reasonable chances of transition to lower secondary grades, especially where these are within the basic education cycle.

5. More rather than less equitable opportunities to learn for children from poorer households, especially girls, with less variation in quality between schools

Obanya [6] defined Access as full and unfettered educational opportunity devoid of all manners of Exclusion; that which is crowned by successful learning and improved life chances for all classes of beneficiaries whose improved knowledge and skills, positive values and attitudes should contribute to reducing socio-economic inequities and poverty in the wider society. While a reductionist view of Access says 'get the children to school', meaningful access says 'take them through school and ensure that they actually learn'. [8]

Children from the poorest (lowest wealth quintile) households, and those with mothers having less than primary education, are largely excluded from school. Both boys and girls from such backgrounds are much less likely to be in school at all ages. Those children with this socio economic background that do start school, will normally start late at the age of 10-11. The high cost of schooling is a major factor limiting attendance. For an average child from the poorest quintile, the total cost (including tuition, uniforms, textbooks, transportation and all other related costs) is one fifth of household income.

Girls from the North, rural areas and poorest families have very low educational attainment.They are least likely to attend school. The percentage of 'out of school' children is highest in the north of the country, ranging from $43 \%$ of boys, to $53-54 \%$ of girls. In the North West region, where ESSPIN operates, a smaller percentage of girls (47\%) than boys $(57 \%)$ attend formal, or integrated religious schools. Girls are less likely to be in the formal secular education system, and more likely to be in non-integrated religious schools, which do not teach at least one of the following subjects: English, Mathematics, Social Studies or Science.

A further factor limiting girls' attendance is that schools are not seen by parents as a safe and secure environment for their female children. There are concerns over the lack of separate and sufficient toilet facilities for girls. The predominance of male teachers and their behaviour is perceived by some parents as a threat to their girl child. There is anecdotal evidence of school-based violence and sexual harassment of girls and female teachers. To secure girls from sexual harassment and exploitation, parents have prevented their daughters from completing school and husbands have prohibited wives from teaching.

Women's overall role in education is limited by the prevailing traditional, socio-cultural structures and practices within an inherently patriarchal society. Women's role in community life focuses mainly on child bearing, child rearing and taking care of the home. The introduction of school based management committees (SBMCs) provides a potential forum where women can participate in the decisions around their children's education.

\subsection{Literature Review}

Davidson [9] stated that with the increasingly supportive policy environment, there has been very rapid expansion in access and participation in ECE. From $1,860,271$ in 2005; total enrolment in nursery preprimary schools increased to 2,538,336, in 2009; and 5,880,842 in 2012. Bakari [10] observed in the same vein, that total enrolment in primary schools has also been on the increase. From 22,861,884 (GER 92.52\% males; $81.92 \%$ females) in 2005 enrolment increased to 24,035,371 (GER $91.78 \%$ males, $88.33 \%$ females) in 2009 and to 26,158,375 (GER 97.65 males, 98.55 females) in 2012. However the increase in total and gross enrolment rate does not reflect the true situation on access and participation of children of primary school going age ( 6-11year olds). For example, the primary school net enrolment rate, despite the increase in number of pupils enrolled, dropped from $61 \%$ in 2007 to $58 \%$ ( $60 \%$ males, $55 \%$ females) in 2010 , implying that more than $40 \%$ of pupils of primary school age (6-11 year old) were out of school [11]. The same was also true for enrolment in JSS with a total enrollment of $3,624,163$ 
(GER 38.60\% males, 33.82\% females) in 2005, 4,435,251 (GER 43.21\% males, 38.39 females) in 2009 and 5,277,527 (GER 46.43\% males, 42.90\% females) in 2012. The implication, according to Global Education First Initiative [12], of the very low GER is that not only are most pupils of JSS going age out-of school, but also that a significant proportion of children who complete primary school are not transiting to JSS despite the seamless transition policy. This is not surprising as some State Ministries of Education and Federal Government Unity Colleges (FUCs) require at least minimum performance on entrance/selection examinations prior to admission to JSS. This process leaves out children who do not attain predetermined cut-off marks and are 'pushed out' to join the growing population of out-of-school FME [13].

ESSPIN's work and research at school and community levels across six Nigerian states provides insights into the relationships between expansion, quality, equity and inclusion. Detailed information on school and pupil characteristics allows for reporting on inequalities in education outcomes, contrasting programme-supported and all schools in those states. Pupils' gender, poverty, location, age and language group are analysed and related to teacher, head teacher and school characteristics; as are inclusive policies and practices in classrooms, schools and communities through school-based management committees (SBMCs). This paper draws on a range of progress reports and impact studies, notably a community-based qualitative study on SBMC interventions and the 2014 Composite Survey, to document ESSPIN's progress on Inclusion in the 2014/15 programme year, in line with 2014 Inclusion Approach Paper.

\subsection{Research Objectives Purpose of the Study}

The purpose of this study is to assess the effects of ESSPIN's integrated School Improvement Programme (SIP), and to report on the quality of education in the six ESSPIN-supported states. The surveys address five output indicators: teacher competence, head teacher effectiveness, school development planning, SBMC functionality, and inclusive practices in schools. They also address one outcome indicator, school quality, and one impact indicator, pupil learning achievement.
- Is there any improvement in enrolment as a result of DFID/ESSPIN intervention?

- Do boys in school learn more than girls?

- Are students from poorer families, overage students, and speakers of minority languages learning less than their peers?

- Are female teachers and head teachers more competent or effective than their male colleagues?

- And are any such gaps in learning or competence larger in ESSPIN schools than in other schools?

\section{Methodology}

A stratified sampling design was used .The survey covered primary schools in the six ESSPIN states-Enugu, Jigawa, Kaduna, Kano and Lagos. The sampling frame was compiled using the annual school census (ASC) with stratification by ESSPIN phases and whether or not the schools had participated in an earlier attempt to measure learning outcomes, the 2010 Measurement of Learning Achievement (MLA) exercise. The sample design took account of MLA participation in order to allow comparisons between that 2010 round of data collection and the CS1.

Teachers were randomly sampled within selected. Teachers within each school were sampled from the population present in the school on the day of the survey visit and from those teaching grades 1-6 in the present term, using the school's teacher attendance register. Fieldwork teams asked head-teachers to complete such a register in cases where it had not already been done for the day of the visit. Team supervisors entered the number of eligible teachers into the computer-assisted personal interviewing (CAPI) system, which would then randomly select 6 to be sampled.

Pupils were sampled from the pupil registers for grade 2 and 4 classes. The sample size of four pupils per test per school remained the same between CS1 and CS2. In cases where the registers were not available or had been found to be inaccurate, data collectors went to the classrooms and counted pupils instead. Again, the CAPI system randomly assigned pupils to be sampled.

Table 1. Sample coverage in Schools

\begin{tabular}{|c|c|c|c|c|c|c|c|c|c|}
\hline \multirow[b]{2}{*}{$\begin{array}{c}\text { Intended } \\
\text { sample }\end{array}$} & \multirow[b]{2}{*}{ Actual } & \multirow[b]{2}{*}{ Interview } & \multicolumn{4}{|c|}{ Teachers } & \multicolumn{3}{|c|}{ Pupil tests } \\
\hline & & & Lesso & ved & Tests & L2 & L4 & N2 & N4 \\
\hline Enugu & 105 & 105 & 532 & 519 & 494 & 388 & 395 & 384 & 382 \\
\hline Jigawa & 105 & 103 & 430 & 425 & 415 & 393 & 399 & 396 & 398 \\
\hline Kaduna & 140 & 140 & 638 & 625 & 586 & 539 & 521 & 538 & 517 \\
\hline Kano & 175 & 170 & 773 & 764 & 645 & 667 & 635 & 669 & 632 \\
\hline Kwara & 105 & 105 & 545 & 538 & 483 & 394 & 393 & 397 & 391 \\
\hline Lagos & 105 & 105 & 569 & 545 & 526 & 415 & 410 & 413 & 409 \\
\hline Total & 735 & 728 & 3487 & 3416 & 3150 & 2796 & 2753 & 2797 & 2729 \\
\hline
\end{tabular}

Note: Throughout this report, $\mathbf{L} \mathbf{2}$ refers to the grade 2 literacy test, $\mathbf{L} \mathbf{4}$ to the grade 4 literacy test, $\mathbf{N} \mathbf{2}$ to the grade 2 numeracy test, and $\mathbf{N} \mathbf{4}$ to the grade 4 numeracy test. 


\subsection{Analysis of Findings}

\section{WHAT IS THE IMPACT OF SCHOOL IMPROVEMENT PROGRAMME ON ENROLMENT?}

Table 2. Enrolment of girls and boys in primary grades of government schools, 2009-13 Ratio of girls to boys in primary grades

\begin{tabular}{|c|c|c|c|c|c|}
\hline \multicolumn{5}{|c|}{$\%$ schools with equal numbers of girls and boys $(+/-5 \%)$} & \multirow[t]{2}{*}{ Parity change } \\
\hline & 2009 & 2013 & 2009 & 2013 & \\
\hline Enugu & 0.98 & 0.95 & 21 & 18 & -0.03 \\
\hline Jigawa & 0.70 & 0.76 & 5 & 7 & 0.06 \\
\hline Kaduna & 0.81 & 0.86 & 14 & 17 & 0.05 \\
\hline Kano & 0.90 & 0.97 & 6 & 9 & 0.07 \\
\hline Kwara & 0.89 & 0.91 & 14 & 15 & 0.02 \\
\hline Lagos & 1.04 & 1.04 & 28 & 26 & 0.00 \\
\hline
\end{tabular}

\subsection{Enrolment of Boys and Girls}

Before discussing pupil learning outcomes, we briefly present and discuss descriptive statistics in Table 2 on the enrolment of girls and boys in primary grades of government schools between 2009 and 2013 obtained from the ASC. At the same time as ESSPIN has been reaching more schools, there have been large changes in enrolment in some of the states. In the northern states Jigawa, Kaduna and Kano - the number of pupils in each school has increased by over one-sixth. Growth in the number of schools and teachers has not kept pace. In Kaduna and Kano, enrolment increased disproportionately fast in ESSPIN schools. Total enrolment increased by over $60 \%$ between $2009 / 10$ and $2013 / 14$ in ESSPIN schools in Kano. This may reflect ESSPIN support to schools to improve access, especially for children from disadvantaged backgrounds. There were substantial increases in the pupil-teacher ratio in all states except Enugu. In Kano and Lagos the pupil-teacher ratio increased fastest in schools with the most ESSPIN intervention. This may to some extent have offset any effects of an improvement in school quality due to ESSPIN.

The ratio of girls to boys in primary grades is farthest from 1 (i.e. fewer girls than boys) in Jigawa and Kaduna, and closest to equality in Kano, Lagos and Enugu. However, both Jigawa and Kaduna seem to be moving gradually towards greater equality. The southern states (Enugu, Kwara, and Lagos) have the highest proportion of schools with equal numbers of girls and boys in primary grades (though Kaduna's figures seem comparable to Kwara at least). Jigawa, Kaduna and Kano have all progressed more than the other states in coming closer to equal numbers of boys and girls.

Do boys in school learn more than girls? Are students from poorer families, overage students, and speakers of minority languages learning less than their peers? Are female teachers and head teachers more competent or effective than their male colleagues? And are any such gaps in learning or competence larger in ESSPIN schools than in other schools?

The paper attempts to answer these questions by focusing on differences in pupil learning outcomes by gender, wealth, location, language, age, and disability; and on gender differences in teacher competence and head teacher effectiveness. Our key indicators are the results of pupil tests in literacy and numeracy at grade 2 and 4, and standards of teacher competence and head teacher effectiveness based on interview responses and lesson observations .In each case we disaggregate by the relevant dimension (gender, wealth, etc.) and apply statistical tests to assess whether any differences in our estimates are likely to have occurred by chance or to represent real differences in the population.

Where relevant and feasible, we also disaggregate further by whether or not the school received ESSPIN's set of interventions aiming at strengthening the capability of primary schools to provide improved learning outcomes. ESSPIN's SIP aims to provide and support the use of structured materials that ensure teachers can deliver high-quality instruction, to strengthen teachers' own understanding of literacy and numeracy concepts, and to improve academic leadership and school improvement planning by head teachers. It typically works through a two-year modular programme of workshops and school visits, after which schools continue to receive school visits from government officers to help maintain and continue gains in quality. On this note Obanya [14] observed that this disaggregation gives us an indication of whether ESSPIN school improvement interventions are reaching all groups of pupils, teachers and head teachers equally, or benefiting some more than others.

\subsection{Pupil Learning Outcomes}

We discuss differences in pupils' learning outcomes by gender, household wealth, and remoteness of school, language, age and disability. Pupils in both rounds of the survey were administered grade 2 and 4 literacy and numeracy tests. We find no significant gender differences. Pupils from the richest $20 \%$ of households answered twice as many questions correctly as those from the poorest. We find evidence that the poorest children are benefiting disproportionately from ESSPIN's interventions, so that treatment schools have smaller wealth disparities than control ones. On the remoteness of schools, we find that pupils in urban schools performed significantly better than those in rural schools. The rural-urban gap, though less pronounced in ESSPIN schools, is still significant. We do not find any evidence that pupils who predominantly speak a minority language (i.e. not Igbo in Enugu; Hausa 
in Jigawa, Kano and Kaduna; and Yoruba in Kwara) received significantly different marks. Across tests and grades, overage pupils performed better than their counterparts who were age-appropriate for their grades. The pupil tests included a number of questions on assessing various forms of physical disability among sampled pupils; in total, 54 pupils $(\sim 0.5 \%)$ from the CS2 sample were found to be disabled. As these children cannot be taken as a representative sample-and were disabled in different ways-we have not analysed their test results separately.

\subsection{Gender Differences}

Although there appear to be more boys than girls enrolling in some states, the results from the survey suggest that, once in school, boys and girls obtain roughly equal learning outcomes. There was no significant difference between boys and girls in average test scores in literacy and numeracy tests in grades 2 and 4 . This largely corresponds with gender-disaggregated pupil test scores from CS1, where scores on N2, L2, and L4 did not differ significantly along the gender dimension, though girls scored significantly better $(42 \%)$ than boys $(38 \%)$ on the grade 4 numeracy test in CS1.
Table 3. Gender disaggregated pupil learning outcomes in CS2 Mean test score \%

\begin{tabular}{|l|c|c|c|}
\hline & Boy & Girl & Significant diff. \\
\hline Numeracy Primary 2 & 38.2 & 37.3 & \\
\hline Literacy Primary 2 & 29.9 & 30.3 & \\
\hline Numeracy Primary 4 & 33 & 32.9 & \\
\hline Literacy Primary 4 & 28.9 & 30.2 & \\
\hline
\end{tabular}

The differences in enrolment probably mean that the sample of girls in school is more selective than the sample of boys (i.e. the girls are a more able group because less advantaged girls do not attend) so that gender parity in test scores does not imply that schools are equally effective in educating girls and boys.

\subsection{Wealth}

Did poorer pupils perform differently from pupils from wealthier backgrounds on the pupil tests?

In the survey, data on pupil household wealth was collected using a short asset questionnaire administered at the end of the grade 4 literacy and numeracy tests. The data collectors showed grade 4 pupils pictures of common household assets asking the pupil if his/her family had that asset at home.

\section{Question in CS2 on pupil household wealth I just want you to look at some pictures of things. Please look at these pictures one by one and tell me if your family has any of these things in your home.}

\section{Interviewer: point to first picture.}

Does your family have a sofa?

\section{Repeat for subsequent items.}

Sofa, chair, table, mattress/bed, mat, sewing machine, fridge, bicycle, motorbike, car, Generator, fan, radio, TV, computer, mobile phone.

results in a wealth gap - a difference between test scores for the richest and poorest - of 20 percentage points in non-ESSPIN schools, and between 8 to 16 percentage points in schools receiving different levels of ESSPIN exposure.

\section{Figure 2.}

We confirm that this is a significant difference in wealth gap using a statistical model, which we also use to plot the average relationship between wealth, ESSPIN intervention and test scores-the dotted trend lines in Figure 5 (smoothing out some inconsistencies in effect between different levels of ESSPIN intervention to produce an overall trend). Learning outcomes appear to be higher for both rich and poor students in ESSPIN schools compared to non-ESSPIN, but more for the poor students, so that the wealth gap is smaller in ESSPIN schools. However, we are unable to establish causation, because the selection of ESSPIN schools is not random and we do not have data on the wealth of children at different points in time. It is possible that children in ESSPIN schools were more equal at the beginning of the intervention, for example because they are more likely to be in urban or peri-urban areas, where richer and poorer children mix within the same classrooms. Nevertheless, the convergence of rich and poor students in schools with more ESSPIN intervention is at least consistent with a reduction by ESSPIN in the effects of inequality in socioeconomic status on learning outcomes.

Gender differences: We find no significant gender differences in mean pupil test scores across all CS2 schools as well as within ESSPIN and non-ESSPIN schools.

Household wealth: Pupils from the richest 20\% of households answered twice as many questions correctly as those from the poorest, and the correlation between test scores and household assets is stronger for literacy than numeracy. Does being in an ESSPIN school in CS2 dampen the effect of inequality in household assets? We find evidence that the poorest children are benefiting disproportionately from ESSPIN, and that ESSPIN schools have smaller wealth disparities than the control schools.

\subsection{School Location}

Do pupils in schools which are farther away from urban areas, the state capital or local government area (LGA) headquarters have different learning outcomes compared to schools which are less remote? 
Table 4. CS2 pupil test scores in rural and urban schools, by ESSPIN status

\begin{tabular}{|l|c|c|c|c|c|c|c|c|}
\hline & \multicolumn{4}{|c|}{ Control school } & \multicolumn{4}{c|}{ Treatment school } \\
\hline School-level mean (\%) & Rural & Urban & Significant difference & Diff. (pp.) & Rural & Urban & Significant difference & Diff. (pp.) \\
\hline N2 & 31.3 & 47.7 & + & 16.4 & 43.5 & 58.1 & + & 14.6 \\
\hline N4 & 25.5 & 42.1 & + & 16.6 & 33.3 & 46.5 & + & 13.2 \\
\hline L2 & 24.7 & 39.5 & + & 14.8 & 35.7 & 57.2 & + & 21.5 \\
\hline L4 & 20 & 39.3 & + & 14.6 & 29.6 & 55.7 & + & 26.1 \\
\hline
\end{tabular}

\subsection{Rural Schools}

We supplemented the survey data with information from the Annual School Census on whether a school was 'urban' or 'rural' and used this classification to disaggregate average pupil test scores per school for each of the four tests. Within all sampled schools, we find that pupils in urban schools performed significantly better than those in rural schools by factors of 1.5-2, depending on the test. The magnitude of this rural-urban gap is much more pronounced for literacy test scores and more so for grade 4 than grade 2. Urban pupils in grade 4 did twice as well as their rural counterparts on the literacy test.

There are large rural-urban gaps in both ESSPIN and non-ESSPIN schools. For numeracy scores, this gap (in percentage point terms) is greater in the control schools, while for literacy, it is greater in ESSPIN schools. This suggests that ESSPIN may be associated with better outcomes in both rural and urban schools, but has so far had little impact on the size of the gaps between them. Again, however, we are not able to establish causation (or a lack of it), and this pattern may reflect the way that ESSPIN schools were before the intervention rather than what has happened since.

Remoteness of schools: Pupils in urban schools performed significantly better than those in rural schools, by factor of $1.5-2$ (depending on the test). There is a rural-urban gap between both ESSPIN and non-ESSPIN schools. Pupils have lower test scores in schools that are more remote. For every increase of 10 kilometres in distance between the school and the headquarters of the local government authority, average test scores dropped by around one percentage point.

Teacher competence: Overall, $50 \%$ of sampled teachers were female, with wide variation between northern (Jigawa: 14\%) and southern states (Lagos, Enugu $84 \%)$. Female teachers performed significantly better than their male counterparts on almost all the logframe teacher competence criteria for all six states taken together. At the state level, these gender differences are mirrored only in Enugu, Kano and Kwara. The number of female teachers who passed the teacher tests in English and mathematics is twice that of male teachers, and the number of female teachers who met the teacher competence 1 standard is three times the number of male teachers who met the same. Teachers in ESSPIN schools are more than twice more likely to meet the overall teacher competence standard than male teachers in their schools. Female teachers perform significantly better than their male counterparts on spatial inclusiveness, but we find no significant difference in gender inclusive practices between male and female teachers.

Table 5.

\begin{tabular}{|c|c|c|c|}
\hline $\begin{array}{l}\text { Teacher competence in CS2 by gender } \\
\text { groups Teacher competence criteria (\%) }\end{array}$ & Male & Female & Significant difference \\
\hline Knowledge of English/maths curriculum & 26.2 & 44.1 & $\mathrm{~F}$ \\
\hline Use of one or more teaching aid & 95 & 97.6 & \\
\hline $\begin{array}{l}\text { Use of one or more teaching aid, excluding } \\
\text { reading/writing/copying from blackboard }\end{array}$ & 68.2 & 82.4 & $\mathrm{~F}$ \\
\hline Praise more than reprimand & 74.8 & 86.6 & $\mathrm{~F}$ \\
\hline Assigns two or more individual/group tasks & 46.2 & 59.5 & $\mathrm{~F}$ \\
\hline English score (\%) & 39.7 & 53.4 & $\mathrm{~F}$ \\
\hline Mathematics score (\%) & 55.5 & 67.7 & $\mathrm{~F}$ \\
\hline Passes English and mathematics test & 28 & 57.5 & $\mathrm{~F}$ \\
\hline Competence score (CS1 version) & 64 & 73.4 & $\mathrm{~F}$ \\
\hline Meets teacher competence standard (CS1) & 59.5 & 73 & $\mathrm{~F}$ \\
\hline Competence score (CS2 version) & 55 & 68 & $\mathrm{~F}$ \\
\hline Teacher competence standard (CS2) & 13.6 & 40.4 & $\mathrm{~F}$ \\
\hline $\begin{array}{l}\text { Teacher competence standard (CS2) by } \\
\text { gender groups and states }\end{array}$ & & & \\
\hline States & Male & Female & Significance \\
\hline Enugu & 39.8 & 59.0 & $\mathrm{~F}$ \\
\hline Jigawa & 6.9 & 14.1 & \\
\hline Kaduna & 16.5 & 24.1 & \\
\hline Kano & 9.6 & 25.0 & $\mathrm{~F}$ \\
\hline Kwara & 25.5 & 41.8 & $\mathrm{~F}$ \\
\hline Lagos & \multicolumn{2}{|c|}{42.3} & 59.5 \\
\hline
\end{tabular}




\section{Conclusion}

This paper has examined a wide range of indicatorsinclusive practices in schools, SBMC functionality and inclusiveness, and differences in education outcomes along various dimensions of marginalisation .It has asked whether things were getting better over time overall and across the six states, and whether ESSPIN schools are currently doing better than non-ESSPIN schools.

ESSPIN schools are performing better than the control schools in a number of these areas, We find evidence that the poorest children are benefiting disproportionately from ESSPIN, and that ESSPIN schools have smaller wealth disparities than non-ESSPIN ones.

However, the overall situation across ESSPIN states remains well below the programme's standards and may be deteriorating in some cases, such as classroom spatial inclusion, ,. There are wide disparities in pupil's learning outcomes in rural vis-à-vis urban schools and, though these are less pronounced in ESSPIN schools, it is still significant. Similarly, pupils from 'poorer' backgrounds are performing starkly worse than their better-off peers and again, though this disparity is dampened in ESSPIN schools, it is still significant.

Thus, overall, ESSPIN schools appear to be performing better than non-ESSPIN schools in terms of inclusive practices in schools, classrooms and.

In conclusion, inclusive practices in schools, classrooms and SBMCs show major weaknesses across states, and disparities in education outcomes along various dimensions of marginalisation remain vast and challenging, though ESSPIN schools and teachers appear to be performing better than non-ESSPIN schools in most of these areas. This report has thus discussed the state of inclusion practices both within Output 4 schools and across all schools in the six programme states. While low levels of inclusion reflect persistent sociocultural patterns that are beyond the control of ESSPIN, recent large-scale roll-out of interventions has meant that the programme now has direct links with a very large number of schools in the six states. Much of this roll out happened in 2013-14 and so is unlikely to have started having a major impact by the time of our survey, near the end of the 2013-14 school year. Over the next year, it is hoped that the scale-up will start to push up the overall state averages as opposed to just the averages within ESSPIN schools

Understanding the processes underlying this pattern of results is beyond the scope of the composite surveys. However, we can point to some tentative explanations. First, the surveys have focused on ESSPIN intervention up to $2012 / 13$, by which time it reached around one in six schools across the six states as a whole. The interventions can therefore have had only a modest impact on the state-wide results.

Second, pupil enrolments have increased rapidly in some states, and may have increased faster in ESSPIN than nonESSPIN schools. Teacher and school numbers have not kept pace. We do not have a clear picture of how the profile of pupils may have changed or what pressures have been placed on schools, but it is likely that this has made it more difficult to maintain or improve learning outcomes.
Finally, many teachers' own knowledge of English and mathematics appears to be very limited. ESSPIN training includes lesson plans designed with the aim of boosting teachers' subject knowledge as well as helping them to plan and conduct lessons. But it is not clear if this has been sufficient to overcome the limits of teachers' own education.

ESSPIN now faces a particularly challenging situation. It covers a wide range of types of school, but until 2013 they were disproportionately urban and in Kwara and Lagos. The programme will need to address increasingly difficult and entrenched problems such as low levels of teacher literacy, poorly-functioning remote rural schools, and areas affected by conflict, at the same time as operating on a much larger scale than before and in a context of widening access. Nevertheless, if it can maintain at least some of its effectiveness while reaching a much larger number of schools, the composite survey results suggest it could have an important impact on children's learning.

\section{References}

[1] ESSPIN. ESSPIIN Overall findings and technical report. Report number: ESSPIN 060. ESSPIN Community Engagement and Learner Participation team.(2014). Report of SMO/SUBEB Data 2012-14 for Annual Review.ESSPIN/UKAID. 2013.

[2] Härmä, J., Household survey on private education in Lagos. ESSPIN Report No.LG 503.Abuja: ESSPIN. 2011.

[3] Girard, F., "My father didn't think this way"; Nigerian boys contemplate gender equality. New York: Population Council. 2003.

[4] Megill, D. Final sample design and weighting procedures for ESSPIN Second Composite Survey in Nigeria.Unpublished note written for ESSPIN and Oxford Policy Management. 2014.

[5] Johnson, D., Hsieh, J., and Onibon, F.,The quality of education in Nigeria: a baseline study into the conditions of teaching and learning, and learning outcomes in Kano, Kaduna and Kwara. World Bank/DFID CUBE project. 2007.

[6] Obanya, P., Planning and managing meaningful access to education: the Nigerian experience. Centre for International Education, University of Sussex, Department of Education Open Seminar Series. 2010.

[7] Lewin, K. and Sabates, R., Changing patterns of access to education in Anglophone and Francophone countries in subSaharan Africa: Is Education For All pro-poor? CREATE Pathways to Access: Research Monograph No. 52. Centre for International Education, University of Sussex: CREATE. 2011.

[8] Lloyd, C. B. The demography of the classroom in the primary grades; Patterns of enrolment by age and implications for early learning. Hewlett Foundation. 2012.

[9] Davison, A.J., ESSPIN teaching and learning baseline survey summary report. Abuja: ESSPIN 2010.

[10] Bakari, S., Gender and equity in teacher education; a case study from Nigeria. Unpublished PhD thesis. University of Sussex. 2004

[11] DFID Nigeria,Social exclusion and gender inequality assessment. Abuja: DFID Nigeria. 2008.

[12] Global Education First Initiative, Accelerating progress to 2015: Nigeria, Working Paper. A Report Series to the UN Special Envoy for Global Education. New York/Paris:Global Education First Initiative/Good Planet Foundation. 2013.

[13] Federal Ministry of Education, Nigeria digest of education statistics 2006-2010. Abuja: Government printer. 2011.

[14] Obanya, P., Politics and the dilemma of meaningful access to education: the Nigerian story, Consortium for Research on Educational Access, Transitions and Equity (CREATE), PATHWAYS TO ACCESS, Research Monograph No. 56. Centre for International Education, University of Sussex, UK: CREATE. 2011. 
[15] Filmer, D., and Pritchett, L. H. Estimating wealth effects without expenditure data-or tears: an application to educational enrollments in states of India. Demography, 38(1), 2001. 115-132.
[16] Lewin, K., and Ricardo, S. Changing patterns of access to education in Anglophone and Francophone countries in subSaharan Africa: is education for all pro-poor? (Research Monograph 52). CREATE: Centre for International Education, University of Sussex. 2011 